\title{
Children and adolescents: victims who become perpetrators
}

\author{
Arnon Bentovim \& Bryn Williams
}

Irrespective of whether one considers official statistics, the proliferation of clinical referrals, research initiatives, review articles or even media attention, the problem of children and adolescents who sexually abuse other children has become a subject of increased attention. Given the proportion of young abusers who are themselves victims of sexual abuse, understanding the continuities between sexual victimisation and sexually abusive behaviour has been important. Despite the paucity of reliable evidence, it is clear that the majority of children who are sexually abused do not become abusers. Moreover, we know that around half of all young abusers have not themselves been victims of abuse. This paper sets out to consider these issues and highlight potentially important factors in understanding the origins and development of sexually abusive behaviour at an early age.

\section{Patterns of sexually offending behaviour}

The terms sexual 'abuser' or 'offender' have been adopted widely and suggest a homogeneous group of individuals. Yet it is questionable that perpetrating sexual abuse constitutes a single pattern of behaviour or shares a common aetiological basis. For instance, is the adolescent boy who is worried about his masturbatory behaviour in which he uses pictures of little boys to stimulate his fantasies, to be compared to the opportunistic adolescent rapist? Furthermore, when we consider the possible reasons which may lead the adolescent boy to abuse a child sexually, it is clear that a number of categories of abusers emerge. For a proportion of young abusers aggression appears to play an important role, where sexual activity represents an abuse of power. It is not simply a conscious sense of anger and grievance towards the victim (for example, a step- or half-sibling), but more an expression of anger towards rejecting parents, with the victim representing an object to which the abuser can express these feelings.

A different category of abuser may be a young person who is identified with an abusing and aggressive adult figure (Bentovim, 1995). There is also a group of boys who seek out affection and love, which evolves into sexualised behaviour with siblings. This may occur when the siblings have also experienced physical and emotional abuse. These may be cases where boundaries within the family are poor, inter-generational abuse is common, and relationships are commonly sexualised or eroticised.

Much of what is known about the assessment and treatment of adolescent offenders has been influenced by our experience of adult offenders. However, it is important to consider the origins of sexually abusive behaviour within a developmental model. We know that a significant proportion of adult offenders first experience arousal to children during adolescence (Longo \& Groth, 1983). However, sexual development is likely to be more fluid during adolescence and it is unlikely that most young abusers have developed an organised perversion, unlike the adult offender (Becker, 1988). For instance, some boys describe sexually abusive behaviour triggered by flashbacks to their own abusive experiences, which in turn organises their sexual activities during pubertal development. It was only in a minority of cases that we have worked

Arnon Bentovim is Honorary Consultant Psychiatrist to Great Ormond Street Hospital, the Tavistock Clinic and Honorary Senior Lecturer at the Institute of Child Health (34 Great Ormond Street, London WC1N 3JH). He established the first comprehensive treatment programme for sexual abuse in 1980, and has researched the characteristics of sexually abused children and their families, the effectiveness of treatment approaches and the origins of abusive behaviour. Bryn Williams is currently training to be a clinical psychologist. Prior to this he was a research psychologist at the Institute of Psychiatry and Institute of Child Health, London. He has a special interest in developmental psychopathology. 
with where these activities develop into an organised sexual perversion.

\section{Sexual victimisation and sexually abusive behaviour}

The majority of young people presenting with sexually abusive behaviour are adolescent boys and the effects on them will be examined. However, there are concerns about a small number of sexually abusive girls and the sexual behaviour problems of younger children (Bentovim, 1991).

As suggested at the outset, sexual victimisation is common in the experiences of many young sexual abusers. A number of studies indicate that between 30 and $70 \%$ of young abusers have been sexually abused (Johnson \& Shrier, 1987; Ryan et al, 1990). The impact of sexual abuse on the individual is well documented (Watkins \& Bentovim, 1992). It is suggested that male children account for $25 \%$ of all victims of sexual abuse (Rogers \& Terry, 1984) but there is considerable variation in the prevalence figures presented in the literature. Peters et al (1986) conclude that $3-31 \%$ of male children and adolescents in clinically referred populations are victims of sexual abuse, compared to $6-62 \%$ for females. Furthermore, Finkelhor (1984) suggests that in the general population between 2.5 and $8.7 \%$ of males have been sexually abused at some time.

A number of reasons might reflect the underreporting of male victimisation. For example, being a male victim of abuse may create anxiety about being unable to protect oneself as a 'man'. Being a potential target of homosexual abuse also increases the likelihood of male victims not seeking help. The evidence concerning the impact of sexual abuse for boys suggests that they may be more prone than girls to adopt an externalising response. It is commonly accepted that externalising disorders are more common in boys, whereas internalising problems (for example, anxiety and depression) are more common in girls. Sansonnet-Hayden et al (1987) and Conte \& Schuerman (1987) argued that sexually abused boys met the criteria for conduct disorder, whereas girls were more likely to be diagnosed as being depressed. In addition to aggression, children may become eroticised through frequent sexual stimulation. Sexualised behaviour is a distinct feature of children who have been sexually abused and is noted in a significant number of younger children (Friedrich, 1993; Hyde et al, 1995).

Finkelhor \& Brown (1986) suggest that sexual abuse traumatises children through four distinct

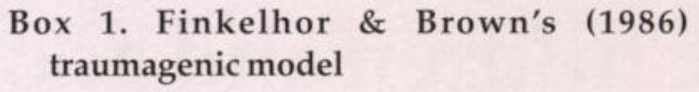

Box 1. Finkelhor \& Brown's (1986) traumagenic model

Traumatic sexualisation

Powerlessness

Stigmatisation

Betrayal

mechanisms (see Box 1), which may account for the response the individual has to that abuse.

Taking traumatic sexualisation as central to this model, one important corollary to any connection between sexual victimisation and abusive behaviour concerns definition. Conceptually, a threshold exists in the minds of clinicians and other practitioners to determine where sexualised behaviour in itself becomes abusive. This is perhaps best summarised in the catalogue of items put forward by a National Children's Home report (1992) on sexually abusive children (see Box 2 ).

Issues of coercion, abuse of power, consent and aggression must be considered within the parameters set out by the report. The age disparity between the victim and abuser has traditionally been considered important, although it is also necessary to consider the nature of the behaviour, the context and the developmental level of those involved (Cantwell, 1988).

Box 2. Questions in determining at what point sexualised behaviour becomes abusive

What is the nature of the alleged abuse?

Is the activity age-appropriate for both victim and perpertrator?

Over what period did the behaviour occur?

Has the behaviour changed over time, e.g. becoming more frequent or deviant?

Is there evidence of bribery, coercion or overt aggression?

What is the victim's experience of the sexual experience, e.g. has the victim blamed themselves for the action taking place?

Is there evidence that the victim has been encouraged to keep the behaviour a secret?

Does the abuser target a particular type of victim?

What are the nature of the sexual fantasies of the alledged abuser, which may have implications for further abuse? 


\section{Development of sexually abusive behaviour}

Given that only around $50 \%$ of young abusers have experienced sexual victimisation themselves, consideration needs to be given to the other potentially important factors. A number of studies have indicated that a proportion of young abusers have experienced physical abuse and neglect (Seghorn et al, 1987; Deblinger et al, 1989). The association made between offending and prior physical abuse is also related to comorbidity with conduct disorder and, later, antisocial personality disorder, which has been identified in a number of sexually offending populations (Kavoussiet al, 1988).

By including individual, familial and social factors (Watkins \& Bentovim, 1992; Vizard et al, 1995) it is possible to begin constructing models of offending behaviour, which help in conceptualising the origins of offending behaviour within a developmental framework. Becker (1988) has produced a model that includes a broad range of factors (see Box 3). Adding to this, and focusing more specifically on the transition from victim to perpetrator, Watkins \& Bentovim (1992) have set out a model detailing the risk factors likely to be associated with becoming an abuser (Box 4). This model incorporates the victimisation experience

Box 3. Becker's (1988) factors influencing the development of sexually abusive behaviour

Individual factors

Social isolation

Impulse conduct disorder

Limited cognitive abilities

History of physical/sexual abuse

Family factors

Parent(s) engage in coercive sexual behaviour

Family belief system supportive of coercive sexual behaviour

Parent(s) have poor interpersonal skills and lack empathy

Social factors

Society supportive of coercive sexual behaviour

Society supportive of the sexualisation of children

Peer group behaves in an antisocial way
Box 4. Watkins \& Bentovim's (1992) factors influencing the development of sexually abusive behaviour

Gender

Male (linked to temperamental factors)

Abuse

Male

Close relative

Multiple perpertrators

Type of abuse

Repeated

Long duration

Greater severity

Age of child

Impact is greater with younger children

Effects

Anxious sexualisation as a result of own victimisation

Externalising coping adaption (influenced by concurrent experience of physical abuse)

Sexual identity confusion

Identification with the agressor

\section{Diagnosis*}

Conduct disorder

Post-traumatic stress disorder

Attention deficit disorder

Learning difficulty

General immature functioning

*When present, the likelihood of externalising responses is increased

as being salient in any prediction of abusive behaviour, along with the effects of abuse and the possible outcomes. These models emphasise the continuities between sexual victimisation and abusive behaviour.

As part of a joint research initiative between the child sexual abuse team at Great Ormond Street Hospital and the Institute of Child Health, a study has recently been completed investigating the origins of sexually abusive behaviour in adolescent boys aged 11-15 years. The research team ${ }^{1}$ was multi-disciplinary, and the study was designed as a hypothesis-generating investigation of four groups of boys who were either victims and/or

1.D.Skuse (child psychiatrist), A. B. (child psychiatrist), J. Hodges (child psychotherapist), J. Stevenson (psychologist), M. Lanyado (child psychotherapist), B. W. (psychologist) and M. New (clinical psychologist). 
perpetrators of sexual abuse and a comparison group:

(a) Victims - boys who were known to have been sexually abused but not known to have abused others.

(b) Victimised perpetrators - boys who were known to have been sexually abused and known to have sexually abused other children.

(c) Non-victimised perpetrators - boys who sexually abused other children but are not known to be victims of sexual abuse themselves.

(d) Antisocial boys - a comparison group of primarily behaviourally disturbed boys with no history of victimisation or sexually abusive behaviour.

From 160 referrals to the child sexual abuse team a comprehensive psychological and psychiatric assessment was made of 86 cases. Detailed studies of the mothers' and boys' social relationships were also conducted. The majority of cases in all four groups were from White families of lower socio-economic status. Many of the victims had experienced severe forms of sexual abuse, including being repeatedly anally abused over a prolonged period of time. The abusers had typically abused children much younger than themselves and the abuse included a wide range of sexual behaviours, most commonly vaginal and anal penetration.

Forty-six of the cases were taken into 12 weeks of an intensive psychotherapeutic, psychoanalytically focused assessment. Half of the sessions were semistructured, by way of introduction using questionnaires and semi-structured interviews. The use of psychoanalytically focused research represents a unique approach in understanding the development of sexually abusive behaviour.

Based on ideas presented in the literature and clinical experience, the evidence collected from the research has been incorporated into a number of potentially important hypotheses for further investigation. The results of the study indicated a number of risk factors. Based on the four-group design, factors were identified which discriminated victimised boys who had become abusers from those who had not. It was also possible to consider differences between boys who had become sexually abusive, but where there was no evidence that they had experienced sexual victimisation. The four risk indicators are presented in Box 5. Particular emphasis was given to the experiences of the boys preceding the onset of their abusive behaviour, or in the case of the victims their sexual victimisation.

The experience of (sometimes prolonged and severe) physical violence, as victim and as witness,
Box 5. Factors placing adolescent boys at risk of sexual perpertrating behaviour, irrespective of early childhood experience of sexual victimisation (Skuse et al, 1997)

Experience of physical violence

Witness of physical violence

Discontinuity of care

Rejection by the family

was common for the young abusers, irrespective of whether or not they were victims of sexual abuse. It has been suggested that violence exposes the child to stress, fear and helplessness, which can become overwhelming and therefore traumatic. When experienced over prolonged periods in early childhood this can adversely affect personality development (Pynooset al, 1993).

As well as violence, the young abusers had experienced the trauma of considerable discontinuity in care. This was compounded by separation from important attachment figures and feeling rejected by the family. The experience of unpredictable and severe adversity in childhood has been found to be related to psychopathology in adulthood (Rutter, 1987). Likewise, those children who do not experience good enough attachments during early childhood and have difficulty in their social relationships may be at increased risk of poor adjustment (Parker \& Asher, 1987; Holmes, 1993). It is evident that although many of the boys had experienced a range in severity of trauma, only a small number showed sign of post-traumatic stress disorder, but a larger number experienced aspects of the traumagenic dynamics referred to earlier.

\section{Frank's story}

One of the unique features of the research described above is the integration of a quantitative methodology with case material collected by the child psychotherapists during the intensive research assessment. Frank's story is a case described in detail by the research team and is published in full elsewhere (Lanyado et al, 1995). Here, the most salient points are presented.

\section{Case example}

Frank was a 12-year-old boy referred to the clinical and research project having engaged in sexual intercourse with his four-year-old half-sister. He was subsequently accommodated with foster parents by the local authority. His behaviour had become increasingly violent and he had been excluded from a number of 
schools. Despite being of average intelligence he was placed in a specialist educational unit for behavioural difficulties.

Frank's early childhood experiences were characterised as abusive, both physically and sexually. Until the age of seven he had been repeatedly abused by his father. He was soley in his father's care from the age of two and was forced to perform sexual acts with a younger female for the voyeuristic satisfaction of his father and other adults invited into the family home. The father had a history of being violent and misusing drugs and alcohol. Although Frank moved to live with his mother at the age of seven, it was not until he was nine years old that he began to talk about the abuse. Two years later Frank sexually abused his half-sister.

This is not uncommon for a number of the boys we have worked with clinically. The exposure to prolonged and severe sexual and physical abuse played a significant part in Frank's early life. The early separation from his mother and discontinuity of care throughout his childhood are also apparent.

He described his abusive action as being triggered by the sight of his half-sister's genitals, which reminded him of the sexual actions he had been forced to participate in earlier in his life. He overcame this internalised resistance to such activities through the cumulative grievance and aggressive fantasies resulting from his earlier sense of powerlessness. The sexualisation he experienced led to powerfully eroticised fantasies which increasingly involved his sister and led to his dangerous behaviour once adolescent development had occurred.

\section{Clinical implications}

Even though they account for only half the subsequent abusers, sexually abused boys must be identified and assessed. Those with history of being rejected by their family, physically and emotionally abused, and being subjected to discontinuous care need special attention.

Programmes are now available (Friedrich, 1995) to work with such boys to deal with not only the direct effects of the abuse, but also the context of risk (rejection and abuse) through individual, group and family work (Hyde et al, 1995). A recent review of empirical studies on treatment of child sexual abuse (Finkelhor \& Berliner, 1995) indicated that treatment focused on the specific effects of sexual abuse was most likely to be successful. Abusefocused treatment aims to assist the child to 'externalise' their experiences, and to construct an account of their experiences which reverses their feelings of responsibility, self-blame, and fears for their future.
Open communication about sexuality and sexual abuse is an essential component, expressing emotions and thoughts, and teaching methods to deal with abuse related to memories and stimuli. More generally, the child's ability to process the sexual abuse experience, both cognitively and emotionally, needs to be enhanced. Self-protection and assertiveness skills are essential tools for the child to acquire. Treatment may include a variety of approaches including cognitive, behavioural, dynamic and systemic models. However, it is unlikely to be effective unless the child is living in a context of emotional support and understanding.

Younger boys showing sexualisation or sexual behaviour disorders require specific work to redefine the rules of appropriate behaviour, detailed assessment and work on the general risk factors (Gil \& Johnson, 1993). Programmes for younger children showing such behaviour patterns may require individual or group work approaches using psychoeducational techniques, with specific attention being paid to their living context. Psychoeducational approaches, which work through a curriculum of information about appropriate and inappropriate sexual behaviours, boundaries (personal and public) and techniques to assert and find emotional closeness without sexualised behaviour, can be effective in combating such inappropriate behavioural patterns. Cognitivebehavioural approaches have the advantage of being time-limited, and deal with painful and stressful issues in smaller sections. The support of other young people can offer help in the confrontation of difficult behavioural problems. It is also essential to look at the context of care, to work with parents to ameliorate disruption, to provide alternative or more satisfactory contact arrangements, and to help parents find other approaches to management which may have been potentially abusive. The approaches described above also need to apply, including protective action, as well as treatment orientated to traumatic effects.

Older boys whose behaviour has become abusive need therapeutic work focused on their offending behaviour (Ryan \& Lane, 1991) and the general risk factors of rejection and physical and emotional abuse, which are likely to be continuing to operate. There is a need for individual, group and family approaches, and a variety of treatment modalities and treatment contexts, including out-patient and residential services, depending on the level of dangerousness' and extent of treatment need. Taking part in a cognitive-behavioural programme on a group or individual basis helps a young person to face his offending behaviour, confronts the denial and cognitive distortion which has justified abusive actions, and identifies the chains or cycles of 
behaviour which lead to and maintain abusive action. It is essential to help the young person dynamically understand a link between their own experiences of abuse, and their abusive actions, and to develop ways of preventing relapse.

The context for abusive behaviour as outlined indicates that it is also important to help a young person confront their own extensive experience of victimisation, not only where this has occurred on a sexual basis, but also their having witnessed pervasive violence between their parents (usually towards the mother) and towards themselves. It is likely that such young people have to be helped to confront the violent identifications which result, and which have a profound effect on their attitudes towards both themselves as young men, and their peers. Provision of alternative models of good parenting, whether through work with parents, placement in foster families, or in residential care, are all essential components of the therapeutic programme, given that young people who abuse other children have maturation on their side. Thus, provision of a different model of care can reinforce work aimed at amelioration of traumatic effects which are re-enacted through a long-standing sense of grievance.

Approaches of this type with adults have been shown to be effective, but to date there have been no controlled treatment programmes which have demonstrated the effectiveness of these approaches with younger people (Vizard et al, 1995).

\section{Conclusions}

Adolescent boys who sexually abuse other children represent an important challenge for mental health professionals and for those working within the child protection system. Adolescent abusers are estimated to be responsible for $30 \%$ of reported abuse. We have set out a number of ideas which may assist us in understanding the origins of such behaviour at an early age. Sexual victimisation has traditionally been considered central to our understanding in the development of sexually abusive behaviour. While it remains an important risk factor, a more complex understanding of the individual's early life experience is necessary. Given that adolescence is a time when sexual preferences are maturing, it represents a window of opportunity for psychiatrists and other mental health professionals to intervene at this developmental stage with the intention of interrupting any potential escalation in sexually offending behaviour.

\section{References}

Becker, J. V. (1988) Adolescent sex offenders. Behaviour Therapist, 11, 185-187.

Bentovim, A. (1991) Childen and young people as abusers. In Children and Young People as Abusers (eds A. Hollows \& $\mathrm{H}$ Armstrong), pp. 5-54. London: National Children's Bureau.

- (1995) Trauma Organised Systems (revised). London: Karnac.

Cantwell, H. B. (1988) Child sexual abuse: very young perpetrators. Child Abuse and Neglect, 12, 579-582.

Conte, J. R. \& Schuerman, J.R. (1987) The effects of sexual abuse on children: a multi-dimensional view. Journal of Interpersonal Violence, 2, 380-390.

Deblinger, E., McLeer, S. V., Atkinsm, M. S., et al (1989) Posttraumatic stress in sexually abused, physically abused, and nonabused children. Child Abuse and Neglect, 13, 403-408.

Finkelhor, D. (1984) Boys as victims: review of the evidence. In Child Sexual Abuse: New Theory and Research (ed. D. Finkelhor), pp. 26-40. New York: Free Press.

- \& Brown, A. (1986) Initial and long term effects: a conceptual framework. In A Sourcebook on Child Sexual Abuse (ed. D. Finkelhor), pp. 10-25. Beverley Hills, CA: Sage.

- \& Berliner, L. (1995) Research on the treatment of sexually abused children: a review and recommendations. Joumal of the American Academy of Child and Adolescent Psychiatry, 334, 1-16.

Friedrich, W. N. (1993) Sexual victimisation and sexual behaviour in children: a review of recent literature. Child Abuse and Neglect, 17,59-66.

- (1995) Psychotherapy with Boys who have been Sexually Abused. Beverly Hills, CA: Sage.

Gil, E. \& Johnson, T.C. (1993) Sexualised Children: Assessment and Treatment of Sexualised Children who Molest. Rockville, MD: Launch Press.

Holmes, J. (1993). John Bowlby and attachment theory. In Modern Makers of Psychotherapy, pp. 40-54. London: Routledge.

Hyde, C., Bentovim, A. \& Monck, E. (1995) Some clinical and methodological implications of a treatment outcome study of sexually abused children. Child Abuse and Neglect, 19, 1389-1400.

Johnson, R. L. \& Shrier, D. (1987) Past sexual victimisation by females of male patients in an adolescent medicine clinic population. American Journal of Psychiatry, 144, 650-652.

Kavoussi, R. J., Kaplan, M. \& Becker, J. V. (1988) Psychiatric diagnoses in adolescent sex offenders. Journal of the American Academy of Child and Adolescent Psychiatry, 27, 241-243.

Lanyado, M., Hodges, J. Bentovim, A., et al (1995) Understanding boys who sexually abuse other children: a clinical illustration. Psychoanalytic Psychotherapy, 9, 231-242.

Longo, R. E. \& Groth, A. N. (1983) Juvenile sexual offences in the histories and adult rapists and child molesters. Joumal of Offender Therapy and Comparative Criminology, 27, 150-155.

National Children's Home (1992) The Report of the Committee of Enquiry into Children and Young People who Sexually Abuse Other Children. London: National Children's Home.

Parker, J.G. \& Asher, S. (1987) Peer relations and later personal adjustment: are low-accepted children 'at risk'. Psychological Bulletin, 102, 357-389.

Peters, S. D., Wyatt, G. E. \& Finkelhor, D. (1986) Prevalence. In $A$ Sourcebook on Child Sexual Abuse (ed. D. Finkelhor), pp. 80-95. Beverly Hills, CA: Sage.

Pynoos, R. S., Sorenson, S. B. \& Steinberg, A. M. (1993) Interpersonal violence and traumatic stress relations. In Handbook of Stress, Theoretical and Clincial Aspects (eds L. Goldberg \& S. Breznitz), (2nd edn), pp. 205-220. New York: Free Press.

Rogers, C. M. \& Terry, T. (1984) Clinical intervention with boy victims of sexual abuse. In Victims of Sexual Aggression: Treatment of Children, Women and Men (eds I. R. Stuart \& J. G. Greer), pp. 70-85. New York: Van Rostrand Reinhold.

Rutter, M. (1987) Psychosocial resilience and protective mechanisms. American Journal of Orthopsychiatry, 57, 3-15.

Ryan, G., Metzner, G. \& Krugman, R. D. (1990). When the abuser is a child: the assessment and treatment of the juvenile sex offender. 
In Understanding and Managing Child Sexual Abuse (ed. K. Oates), pp. 115-140. Sydney: Harcourt Brace Jovanovich.

— \& Lane, S. (1991) Juvenile Sexual Offending. Lexington, KT: Lexington Books.

Sansonnet-Hayden, H., Hayley, G., Marriage, K. et al (1987) The sexual abuse and psychopathology in hospitalised adolescents. Journal of the American Academy of Child and Adolescent Psychiatry, 26,753-757.

Seghorn, T. L., Pretky, R. A. \& Boucher, R. J. (1987). Child sexual abuse in the lives of sexually aggressive offenders. Jourmal of the American Academy of Child and Adolescent Psychiatry, 26, 262-267.

Skuse, D., Stevenson, P., Hodges, J., et al (1997) The Influence of Early Experience of Sexual Abuse on the Formation of Sexual Preferences During Adolescence. London: Institute of Child Health.

Vizard, E., Monck, E. \& Misch, P. (1995) Child and adolescent sex abuse perpetrators: a review of the research literature. Journal of Child Psychology and Psychiatry, 36, 731-756.

Watkins, B. \& Bentovim,A. (1992) The sexual abuse of male children and adolescents: a review of curent research. Journal of Child Psychology and Psychiatry, 33, 197-248.

\section{Multiple choice questions}

1. Which of the following is true or false:

a a minority of children who have been sexually abused go on to abuse other children

b a majority of children who have been sexually abused go on to abuse other children

c a minority of children who sexually abuse other children have been sexually abused themselves

d about half the number of childen who sexually abuse other children have been sexually abused themselves

e a majority of children who sexually abuse other children have been sexually abused themselves.

2. Which of the following factors are frequently associated with abusive behaviours of adolescents to young children:

a normal adolescent exploration associated with developing sexuality

b diverting aggressive experienced from rejecting parents to the victim

c an affectionate close relationship with the mother

d rejection by parents leading to affection seeking which becomes sexualised

e planning and targeting children who have been groomed as fitting into perverse fantasies.

3. Which of the following family background factors are associated with the development of abusive behaviours in young people:

a having a father who has been physically or sexually abused b a family who demonstrate close, warm, enmeshed relationships

c a family who demonstrate rejection and physical violence

d having a mother who has been physically or sexually abused

e a family who provide violent models of relating.

4. To prevent children and young people sexually abusing other children, which combination of factors should be the focus of special intervention:

(i) boys who have been sexually abused

(ii) boys who have been the subject of physical violence

(iii) boys who have witnessed physical violence

(iv) boys who have suffered discontinuous and disrupted care?
a (i) only
b (ii), (iii) and (iv)
c (ii) and (iv)
d (i), (ii) and (iii)
e (i), (ii), (iii) and (iv).

5. Therapeutic work with children and young people who have abused other children needs to focus of which of the following:

a mainly on their experience as victims of violence and abuse

b mainly on their victimising behaviour developing an adequate relapse prevention programme

c mainly on transference or countertransference phenomena rather than behaviour or experiences.

d mainly on altering the living context of the young person to reduce current rejection and exposure to violence and abuse

e mainly on cognitive-behavioural strategies to deal with behaviour and experience.

\begin{tabular}{|c|c|c|c|c|}
\hline \multicolumn{5}{|c|}{ MCQ answers } \\
\hline 1 & 2 & 3 & 4 & 5 \\
\hline a $T$ & a $F$ & a $F$ & a $F$ & a $F$ \\
\hline b F & b $\mathrm{T}$ & b F & B F & b $\mathbf{F}$ \\
\hline c F & c $\mathrm{F}$ & c $T$ & c $\mathrm{T}$ & c $\mathbf{F}$ \\
\hline d T & d $T$ & d $T$ & d $T$ & d F \\
\hline e F & e $\mathrm{T}$ & e $\mathrm{T}$ & e $T$ & e F \\
\hline
\end{tabular}

